\title{
Bicytopenia as a paraneoplastic syndrome for pseudomyxoma peritonei. Hematologic manifestations of a subtle disease
}

This article was published in the following Dove Press journal:

International Journal of General Medicine

2 March 2015

Number of times this article has been viewed

\author{
Ciprian Tomuleasa ${ }^{1,2}$ \\ Bobe Petrushev ${ }^{2}$ \\ Madalina Vedean ${ }^{2}$ \\ Alexandru Irimie ${ }^{2,3}$ \\ Florin Zaharie ${ }^{2}$ \\ Ana-Maria Rosu' \\ Delia Dima' \\ Andrei Cucuianu',2 \\ 'Department of Hematology, Ion \\ Chiricuta Oncology Institute, ${ }^{2}$ luliu \\ Hatieganu University of Medicine and \\ Pharmacy, ${ }^{3}$ Department of Surgery, \\ Ion Chiricuta Oncology Institute, Cluj \\ Napoca, Romania
}

Correspondence: Ciprian Tomuleasa Strada Gheorghe Marinescu No 23, 400339, Cluj Napoca, Romania Email ciprian.tomuleasa@umfcluj.ro

\section{Dear editor}

We have read with great interest the paper of de Oliveira et al, in which the authors report the case of a 76-year-old woman who presented with increased abdominal girth and dyspnea for 2 weeks. ${ }^{1}$ After extensive investigations, the patient was diagnosed with an abdominal pseudomyxoma peritonei and underwent right oophorectomy, omentectomy, and pseudomyxoma debulking. This disease is correctly characterized by the physicians as ranging from benign to borderline, to frankly malignant behavior and therefore, tends to be associated with misdiagnosis. This leads to its discovery in advanced stages, making this disease a challenging entity with potentially fatal complications. The described clinical scenario of pseudomyxoma peritonei is a pseudomyxoma clinically present with a variety of unspecific and uncommon signs and symptoms, except in advanced disease, when it is complicated by an increased abdominal girth and complaints of abdominal pain related to intestinal obstruction. The obstruction appears as a result of disseminated mucinous tumor cells and ascites, presenting at laparotomy with "jelly belly". The best diagnostic tool is a computed tomography (CT) exam, ${ }^{2}$ which shows a characteristic pattern of mucinous accumulation, even though magnetic resonance imaging (MRI) T1- and T2-weighted techniques permit a very sensitive differential diagnosis between mucus and ascites. Tumor markers are used for the follow up of patients that undergo debulking surgery.

All these investigations were used by our colleagues who reported that their case had an absence of leukocytosis, with neutrophilia and an increased value for C-reactive protein. In the current letter, we would like to point out that hematologic parameters associated with pseudomyxoma peritonei are not necessarily the ones described in the current case report as we have experience with a similar tumor with bicytopenia, confirmed by a bone marrow aspiration. As we have no clear reason for the clinical evolution, we can classify the bicytopenia as a paraneoplastic syndrome instead of pseudomyxoma peritonei.

\section{Acknowledgment}

This paper was published under the frame of European Social Fund, Human Resources Development Operational Programme 2007-2013, Project number POSDRU 159/1.5/138776.

\section{Disclosure}

The authors report no conflicts of interest in this work. 


\section{References}

1. de Oliveira AM, Rodrigues CG, Borges A, et al. Pseudomyxoma peritonei: a clinical case of this poorly understood condition. Int $J$ Gen Med. 2014;7:137-141.
2. Kreel L, Bydder GM. Computed tomography of fluid collections within the abdomen. J Comput Tomogr. 1980;4(2):105-115. 


\section{Authors' reply}

\author{
Ana Maria de Oliveira' \\ CG Rodrigues' \\ A Borges ${ }^{2}$ \\ A Martins' \\ SL Dos Santos ${ }^{3}$ \\ F Rocha Pires ${ }^{4}$ \\ J Mascarenhas Araújo 2 \\ J Ramos de Deus'
}

'Department of Gastroenterology, ${ }^{2}$ Department of Internal Medicine, ${ }^{3}$ Department of Pathology and Anatomical Sciences, ${ }^{4}$ Department of Surgery, Pathology and Anatomical Sciences,

Prof Doutor Fernando Fonseca Hospital, Amadora, Portugal

Correspondence: Ana Maria de Oliveira

IC 19, 2720-276 A madora, Portugal

Tel +35 I 963867012

$\mathrm{Fax}+35 \mathrm{I} 214345566$

Email anaoliveira.fml@gmail.com

\section{Dear editor}

We thank Tomuleasa et al for their perceptive comments. In their letter, entitled "Bicytopenia as a paraneoplastic syndrome for pseudomyxoma peritonei. Hematologic manifestations of a subtle disease", they mention that they have experience with pseudomyxoma peritonei with bicytopenia.

As we mentioned in our case report, a 76-year-old woman presented to us with increased abdominal girth and dyspnea for 2 weeks. On work-up, she was diagnosed as a case of pseudomyxoma peritonei. Laboratory investigations showed normal hemoglobin, platelet, and white blood cell values. The only change in hematological parameters was neutrophilia.

In fact, there are no typical changes in hemogram in this condition. Pérez-Holanda et $\mathrm{al}^{1}$ and Grupta et $\mathrm{al}^{2}$ both reported clinical cases of pseudomyxoma peritonei with normal values of hematological parameters. In contrast, Kuan et $\mathrm{al}^{3}$ reported a case in which laboratory investigations revealed leukocytosis. Furthermore, in one of the two clinical cases reported by $\mathrm{Li}$ et $\mathrm{al}^{4}$, the patient had anemia.

Indeed, in pseudomyxoma peritonei, there may or may not be changes in hematological parameters. Routine laboratory parameters are seldom helpful in making the diagnosis of pseudomyxoma peritonei. ${ }^{4}$

\section{Disclosure}

The authors report no conflicts of interest in this work.

\section{References}

1. Pérez-Holanda S, García-Lozano J, Rodrigo Sáez L. Incidental pseudomyxoma peritonei of the appendix diagnosed by computed tomography with sagittal reconstruction in a woman suffering from postmenopausal metrorrhagia. Rev Esp Enferm Dig. 2009;101(7):510-512.

2. Gupta S, Singh G, Gupta A, et al. Pseudomyxoma peritonei: An uncommon tumor. Indian J Med Paediatr Oncol. 2010;31(2):58-61.

3. Kuan FC, Hsieh CC, Lee KF, et al. Pseudomyxoma peritonei mimicking acute appendicitis and peritonitis. $J$ Cancer Res Pract. 2012;28(4):170-176.

4. Li C, Kanthan R, Kanthan SC. Pseudomyxoma peritonei - a revisit: report of 2 cases and literature review. World J Surg Oncol. 2006;4:60.
International Journal of General Medicine

\section{Publish your work in this journal}

The International Journal of General Medicine is an international, peer-reviewed open-access journal that focuses on general and internal medicine, pathogenesis, epidemiology, diagnosis, monitoring and treatment protocols. The journal is characterized by the rapid reporting of reviews, original research and clinical studies across all disease areas.

\section{Dovepress}

A key focus is the elucidation of disease processes and management protocols resulting in improved outcomes for the patient.The manuscript management system is completely online and includes a very quick and fair peer-review system. Visit http://www.dovepress.com/ testimonials.php to read real quotes from published authors. 